Témoigner Témoigner. Entre histoire et mémoire

Getuigen Revue pluridisciplinaire de la Fondation Auschwitz

$125 \mid 2017$

Histoire et mémoire de la persécution des

homosexuel-le's par les nazis

\title{
Mémoire(s) en Ukraine : de l'unité à la diversification
}

De Tweede Wereldoorlog herdenken in Oekraïne: eenheid en versplintering

\section{Frédéric Crahay}

\section{(2) OpenEdition}

\section{Journals}

Édition électronique

URL : https://journals.openedition.org/temoigner/6065

DOI : $10.4000 /$ temoigner.6065

ISSN : 2506-6390

Traduction(s) :

De Tweede Wereldoorlog herdenken in Oekraïne: eenheid en versplintering - URL : https://

journals.openedition.org/temoigner/6295 [nl]

Éditeur :

Éditions du Centre d'études et de documentation Mémoire d'Auschwitz, Éditions Kimé

Édition imprimée

Date de publication : 1 octobre 2017

Pagination : 40-49

ISBN : 978-2-930953-01-4

ISSN : 2031-4183

Référence électronique

Frédéric Crahay, « Mémoire(s) en Ukraine : de l'unité à la diversification », Témoigner. Entre histoire et mémoire [En ligne], 125 | 2017, mis en ligne le 24 décembre 2021, consulté le 03 février 2022. URL : http://journals.openedition.org/temoigner/6065 ; DOI : https://doi.org/10.4000/temoigner.6065 
$\rightarrow$ Frédéric Crahay Directeur de la rédaction 'histoire de l'Ukraine est ancienne et riche. La période qui caractérise
ce pays dans les années 1930 et 1940 ne l'est pas moins. Après avoir ce pays dans les années 1930 et 1940 ne l'est pas moins. Après avoir goûté à un semblant d'autonomie à la fin de la Première Guerre mondiale, IUkraine, dont le nom signifie étymologiquement « frontière », se retrouve englobée dans lUnion soviétique dominée par les Russes. Lidée d'une indépendance insuffée pardes honmes come Sinon Petlioura continuerácependant à faire son chenin. Pour mater le peuple ukrainien, Staline Holodomor en Ulraine et que l'on qualifie souvent de génocide daspelée Holodomor en ukraine et que lon qualifie souvent de génocide dans ce pays. Laspect intentionnelde cette famine fait encore parfois débat, mais lampleur du désastre est reconnue jusquen Occident depuis la publication en 1973 de 'A juin 1941 divisera les Ukrainiens en différents camp : un proupes nazies en juin appelé Oranisation des nationalistes ukrainiens et commandé par l'idéotout en rêvant d'une Ukraine indépendante. Cette volonté d'in á llemand, tout en rêvant dune Ukraine indépendante. Cette volonté d indépendance de l'Armé roug de l'Armée rouge seront également mis au travail de façon volontaire dans les Juifs du externination de lépération Reanhardt quivise à exterminer les Juifs du Gouvernement general. On parlera alors de Hilfswilliger, de Trawnik Männer ou encore d Askaris. Un deuxième groupe combattra les nazis tout en étant farouchement anticommuniste et un troisième groupe, lui,joindra ses à le alle la pró à laquelle la plus grande partie de l'Ukraine sera réntégrée à I'Union soviè-

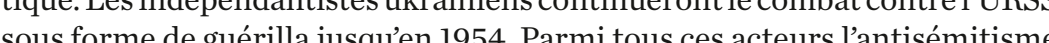
sous forn de par les nationalistes ukrainiens d'être à la solde des bolchéviques, les nazis ont perpétré en Ukraine ce que

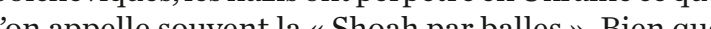
dispersées sur les pays baltes la Pologne etlerestede 'Union soviétique envahie par les nazis, ces tue par balles orchestres par les Einsatzoruppen sont pourent près de Kiev où 33771 Juifs trouvèrent la me le ravin 29 et le 30 op 33 77 J 1941. Les historiens estiment insi qu'entre 1941 et 1944, près d'un illi estint ainsiquentre 1941 et 194, press dun million et demi ('ique par l'Allemagne nazie.

La mémoire de la période 1931-1945 se présente de différentes façons dans l'Ukraine actuelle. À côté de différentes façons dans IUkraine actuelle. À côté

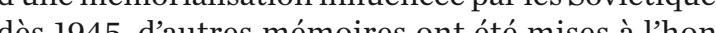
des 1945, d’un neur depuis lindépendance del lokraine en 1991. Les

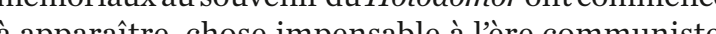
à apparaitre, chóse inpon la mémoàre dumuniste. Depuis les années 2000 , la ménoire du peuple juif dans le martyrologue ukrainien, il en va de focon encore plus discine - il en va de de façon encore plus discrète - pour la mémoire des d'Ukrainis. dukrainiens. La recherche concernant les Juifs en une visibilité accrue avec le travail de recensement les sites d'exécution mené par l'Organisation Yahad In unum dirigée par le père Patrick Desbois. À Kiev, le Ukranian Centre for Holocaust Studies, mené par Anatoly Podolsky tente d'intéresser le public ukrainien à ce passé douloureux, les subsides de ce centre vement de l'étranger. À l'autre extrémité, des symboles nazis ont refait leur apparition lors de la Coupe UEF en 2012 organisée par la Pologne et l'Ukraine dan les rangs des supporters ukrainiens. Plus inquiétant encore, des milices arborant les mêmes symboles se montrent au grand jour depuis la crise du Donbass en 2013. I 

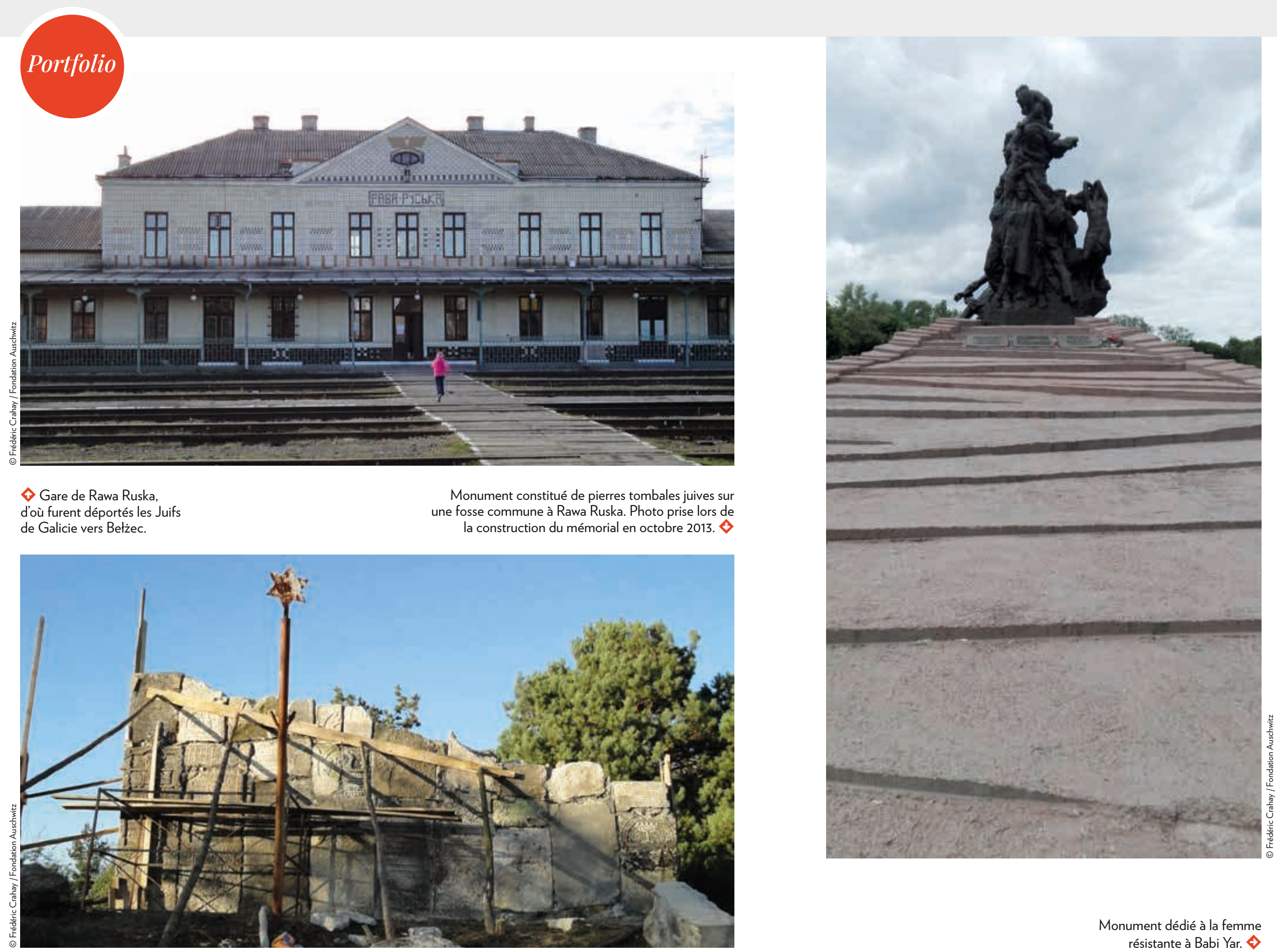

Monument soviétique datant de 1976 à Babi Yar. Les inscriptions en russe, ukrainien et yiddish parlent de civils en omettant le fait que les victimes étaient essentiellement juives.

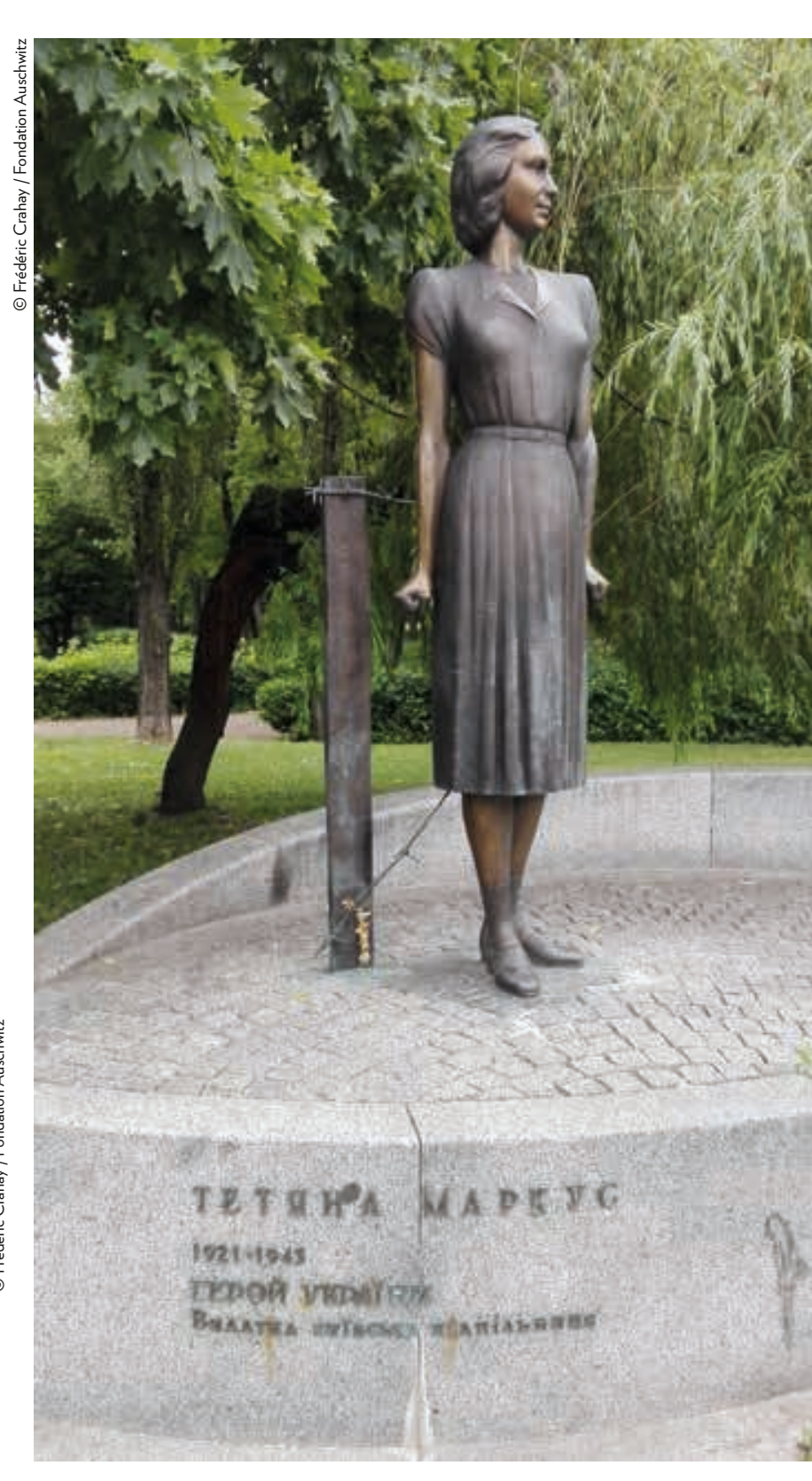




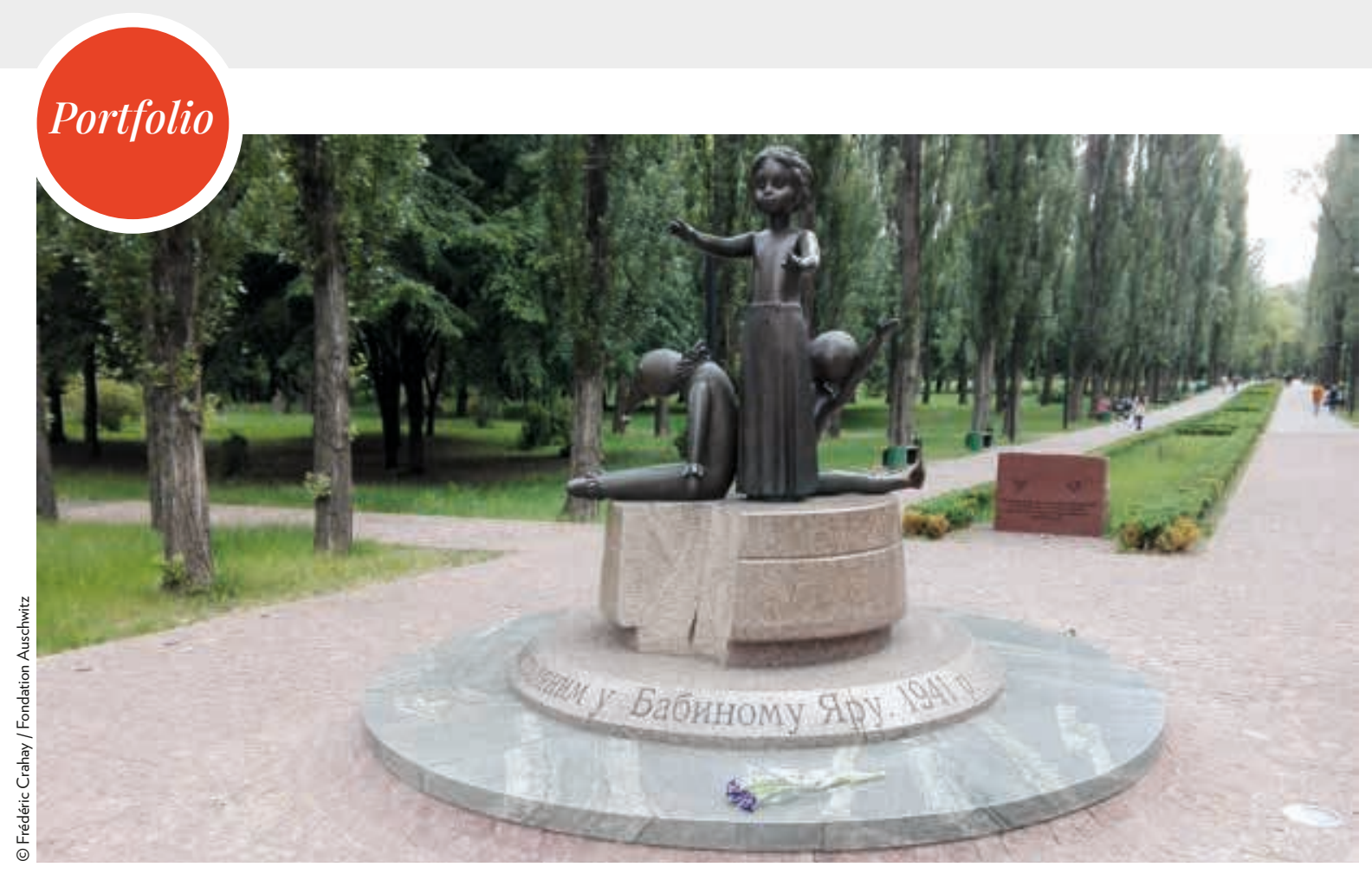

M Monument ajouté en 2001, dédié aux
enfants victimes du génocide à Babi Yar. Babi Yar, monument
dédié aux Tsiganes. $\diamond$

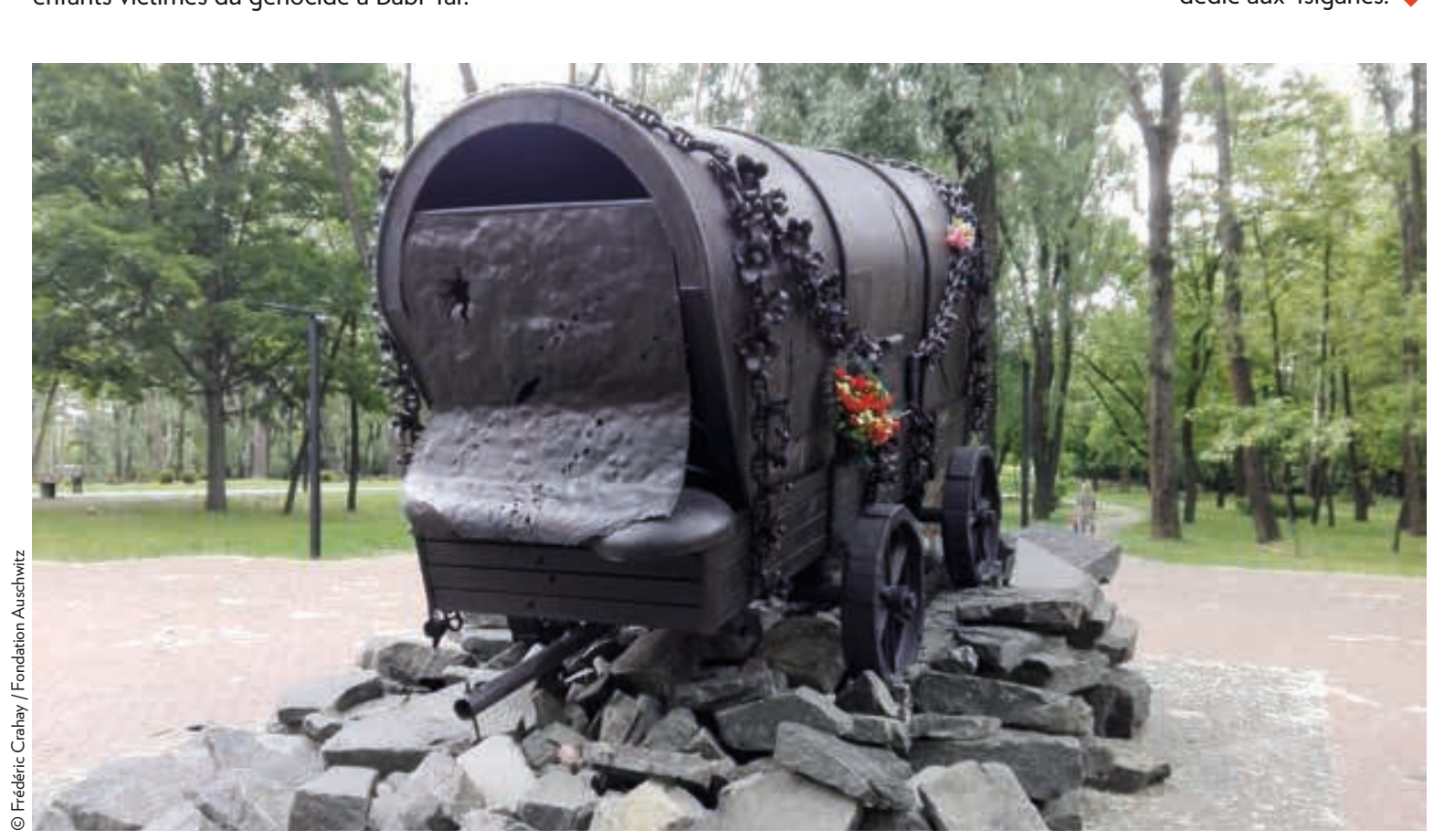

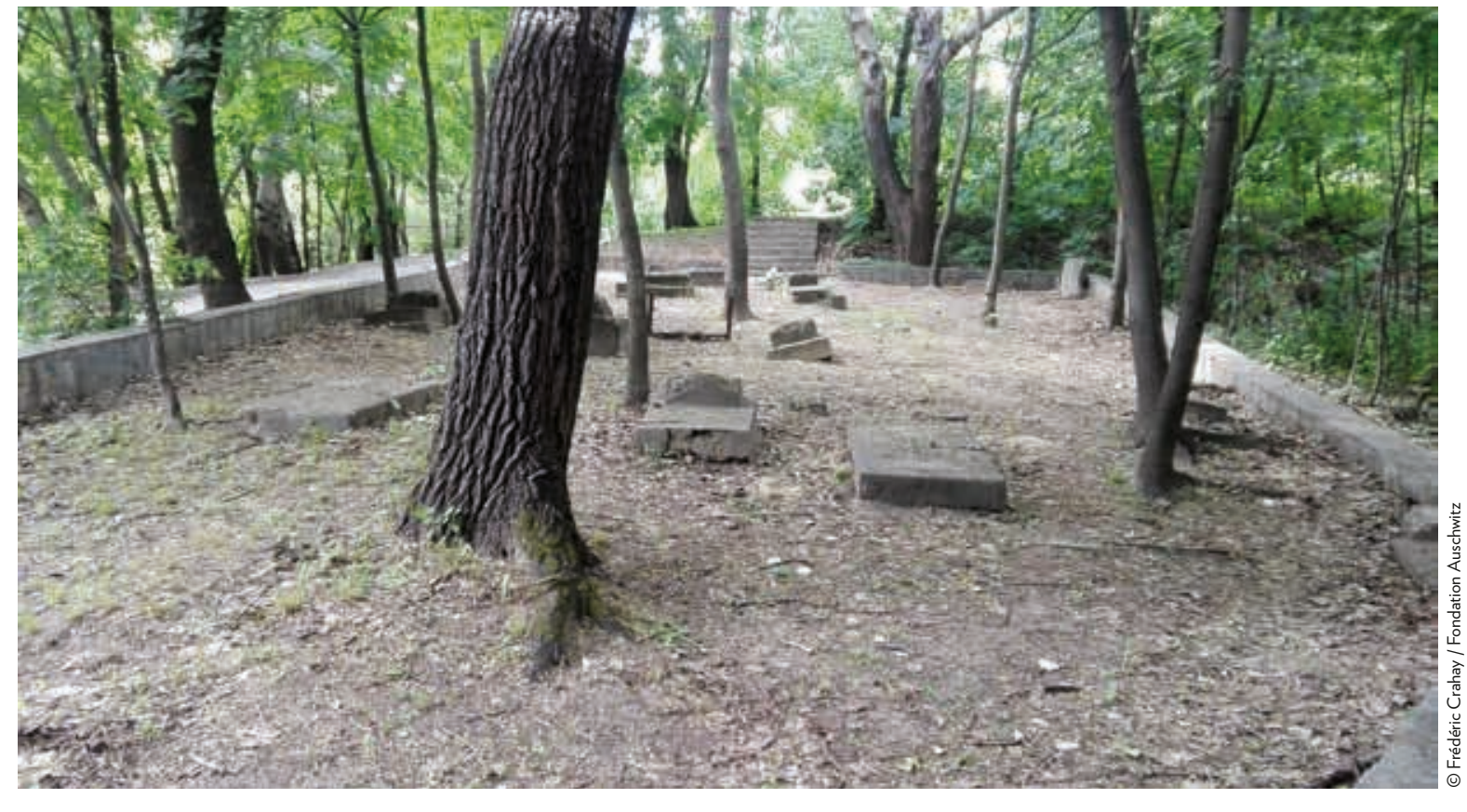

Babi Yar, ruines de l'ancien
cimetière juif détruit lors de la Shoah.

Vestiges du cimetière
juif de Lviv.

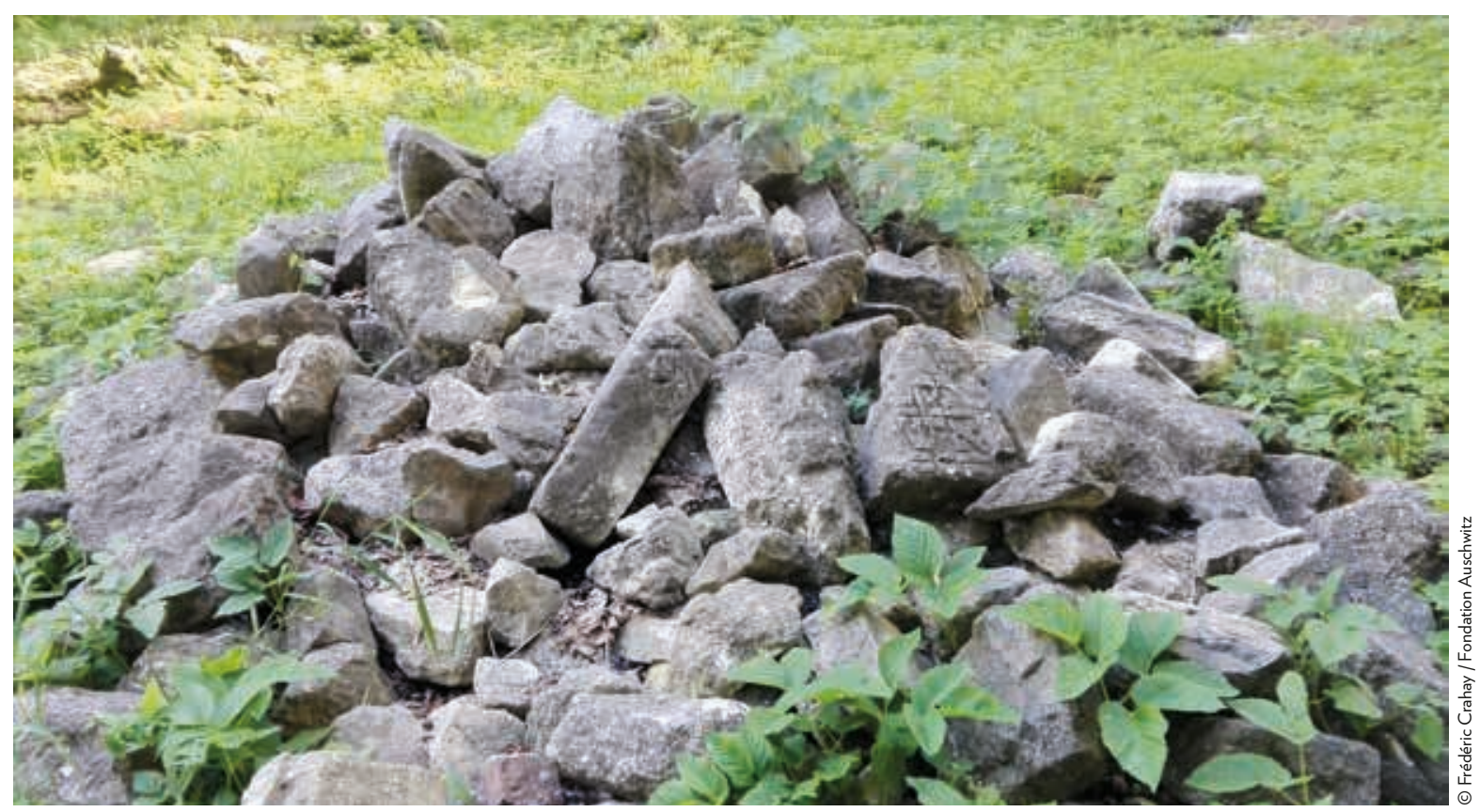




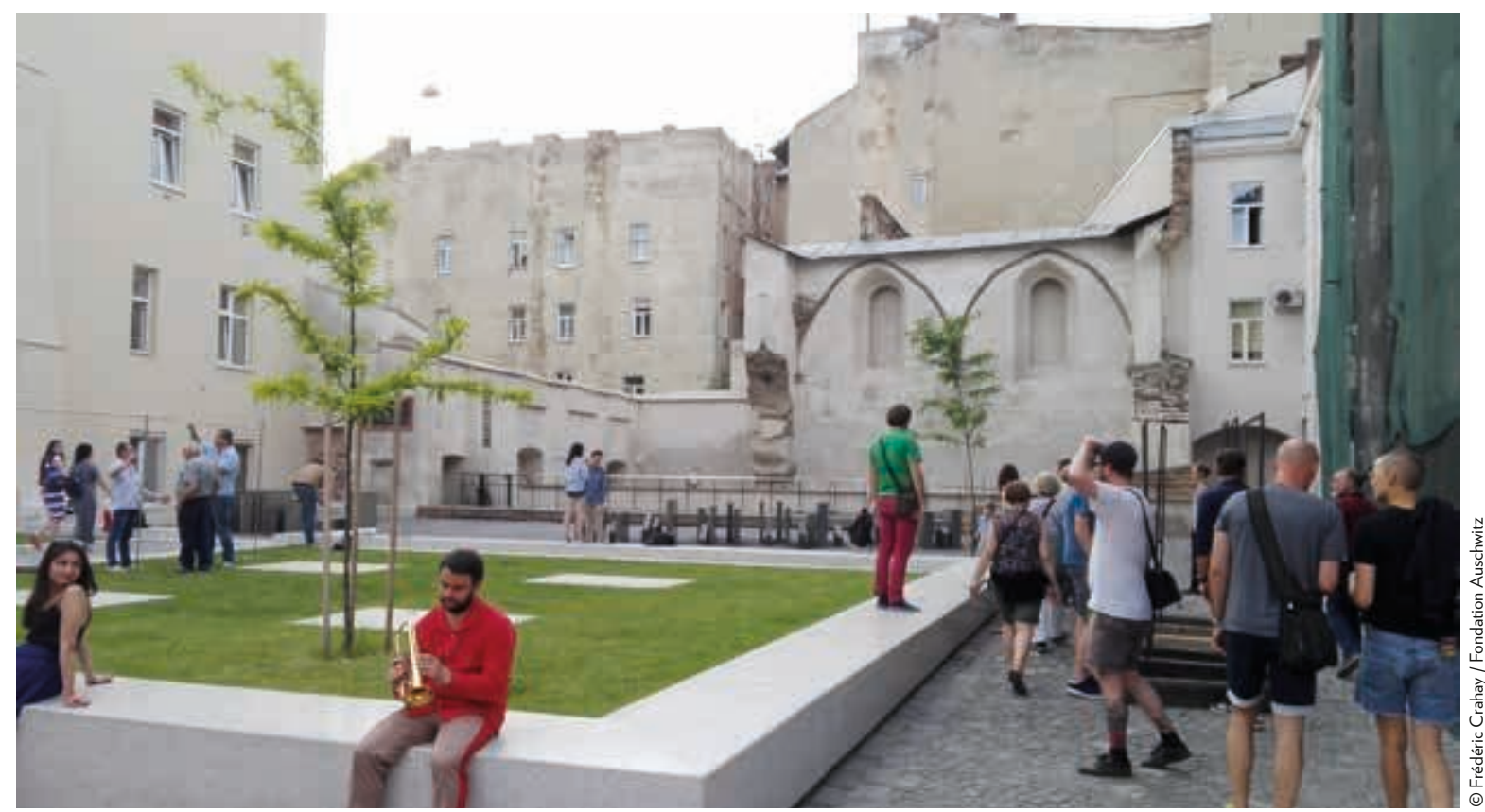

$\checkmark$ Monument commémoratif de l'ancienne

Détail du mémorial de la synagogue Rose d'Or, détruite par les nazis à Lviv. synagogue Rose d'Or à Lviv.
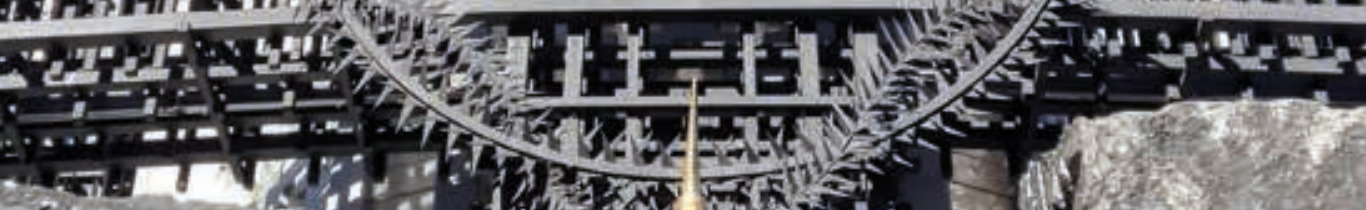

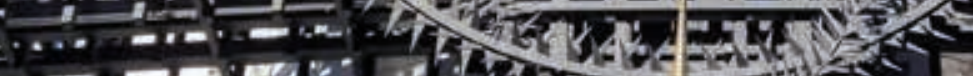

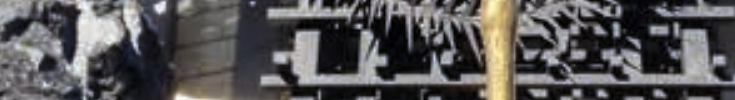

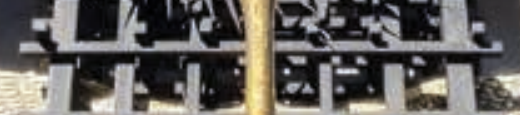
TLTE -RTL सकाष

वध्रा

moges:
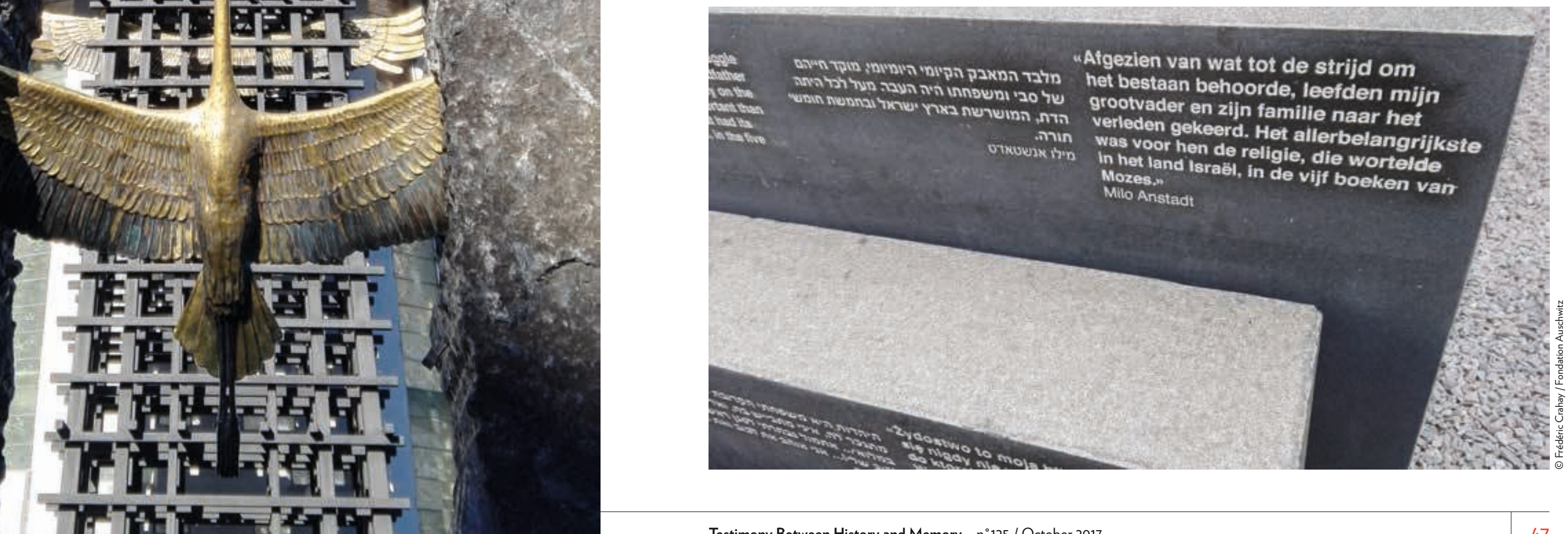


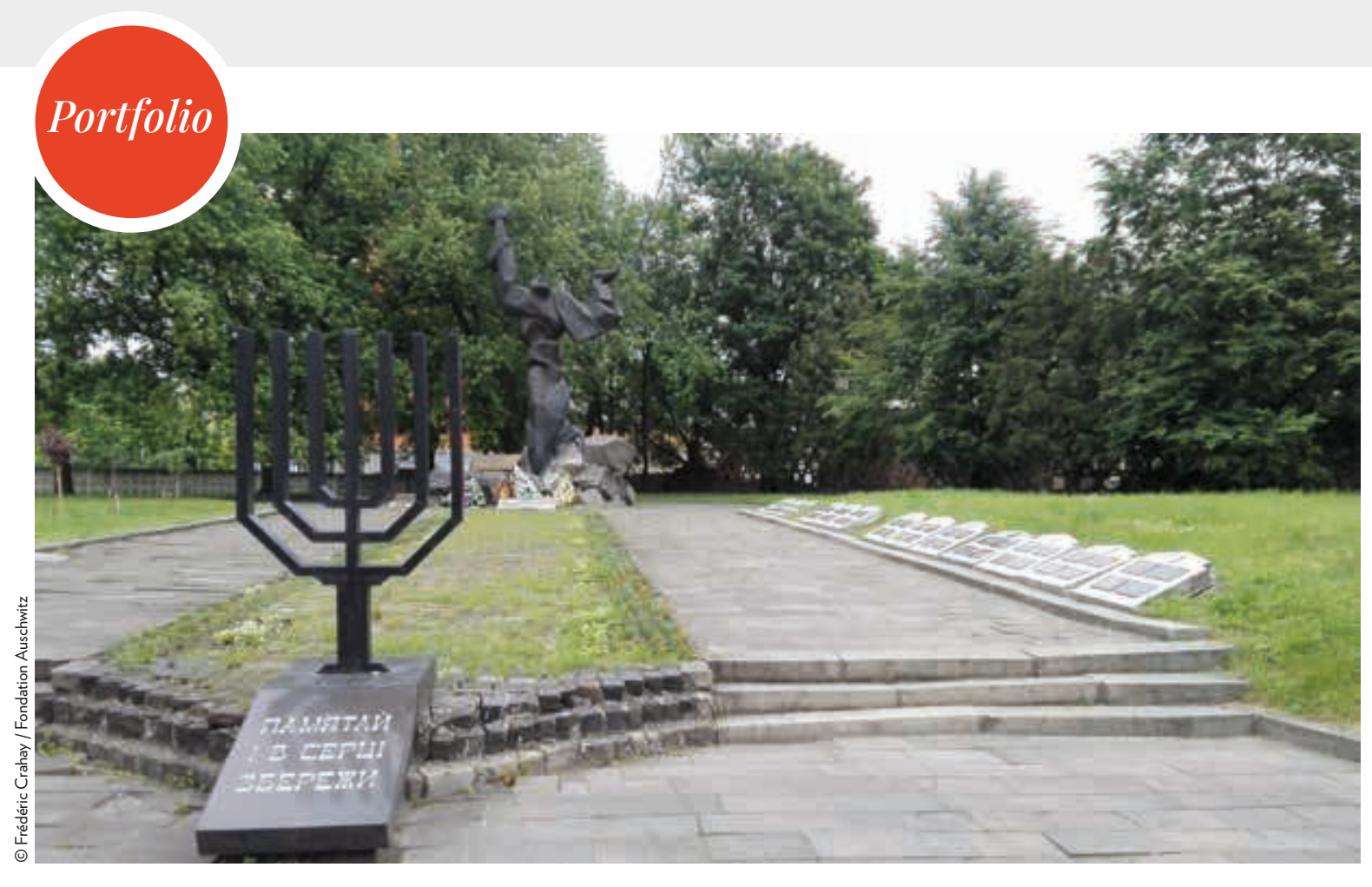

Le mémorial dédié aux victimes

Tombes de soldats ukrainiens de la division SS (a)

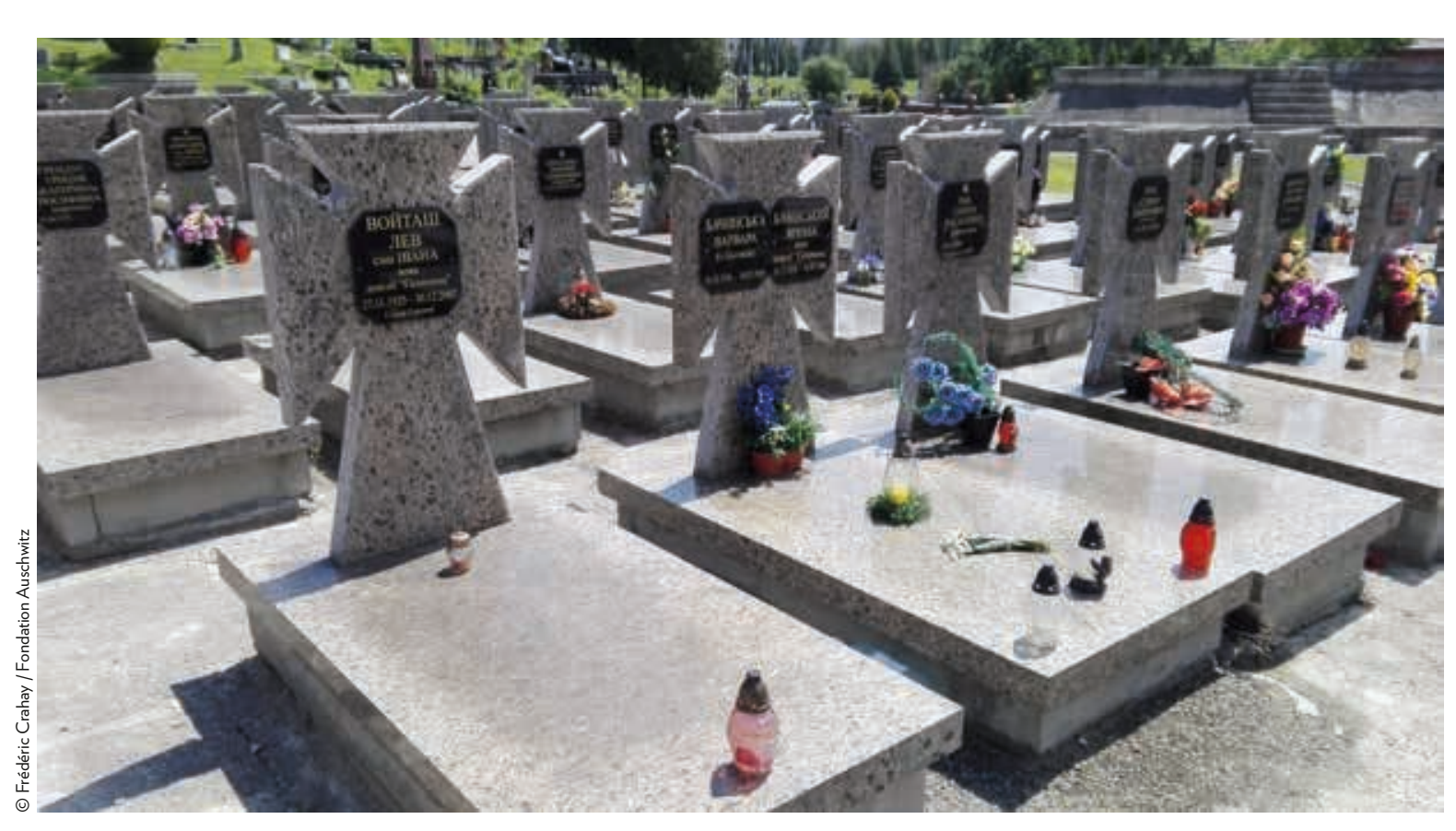

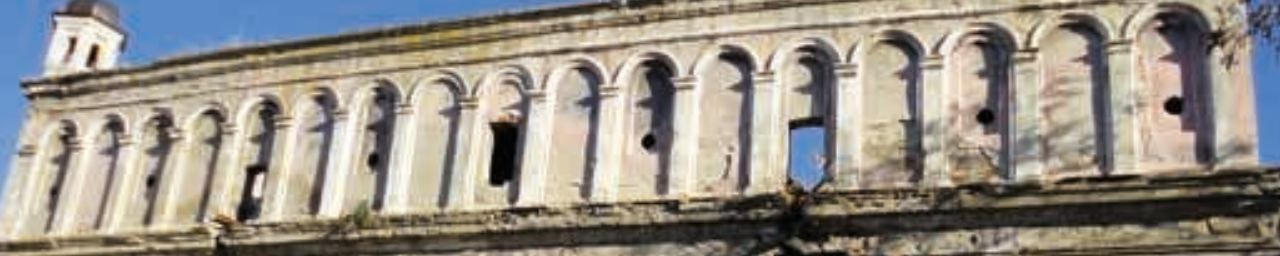

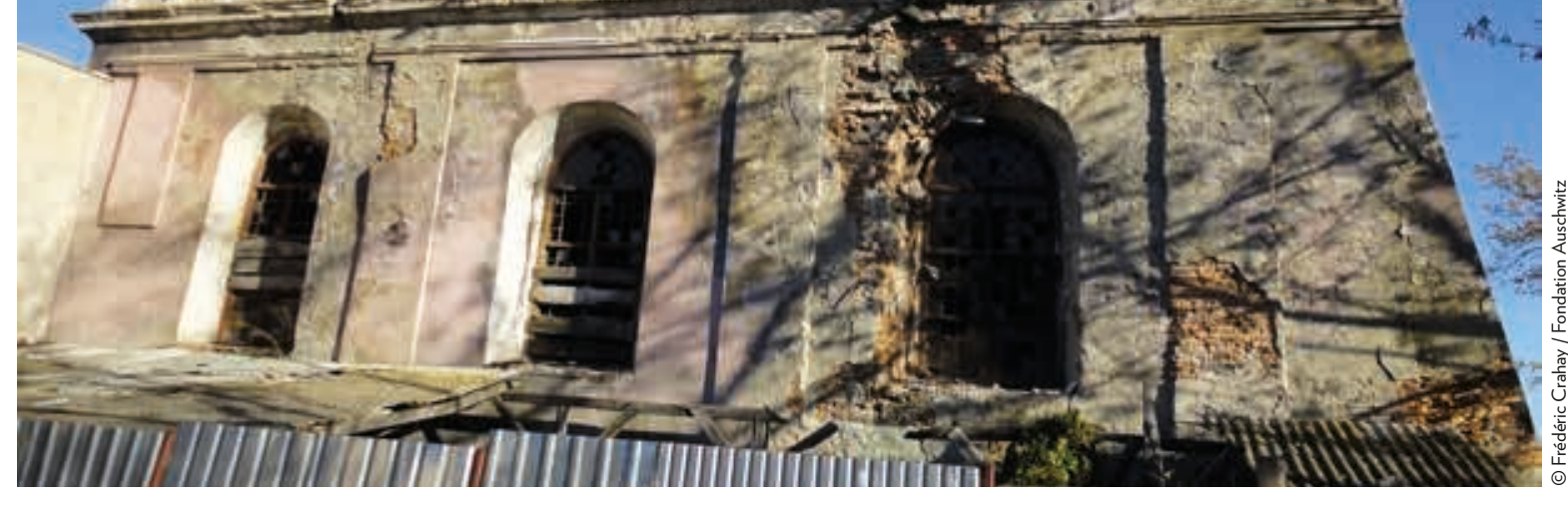

$\widehat{A}$ Ancienne synagogue

Synagogue de Drohobytch
restaurée en 2017.

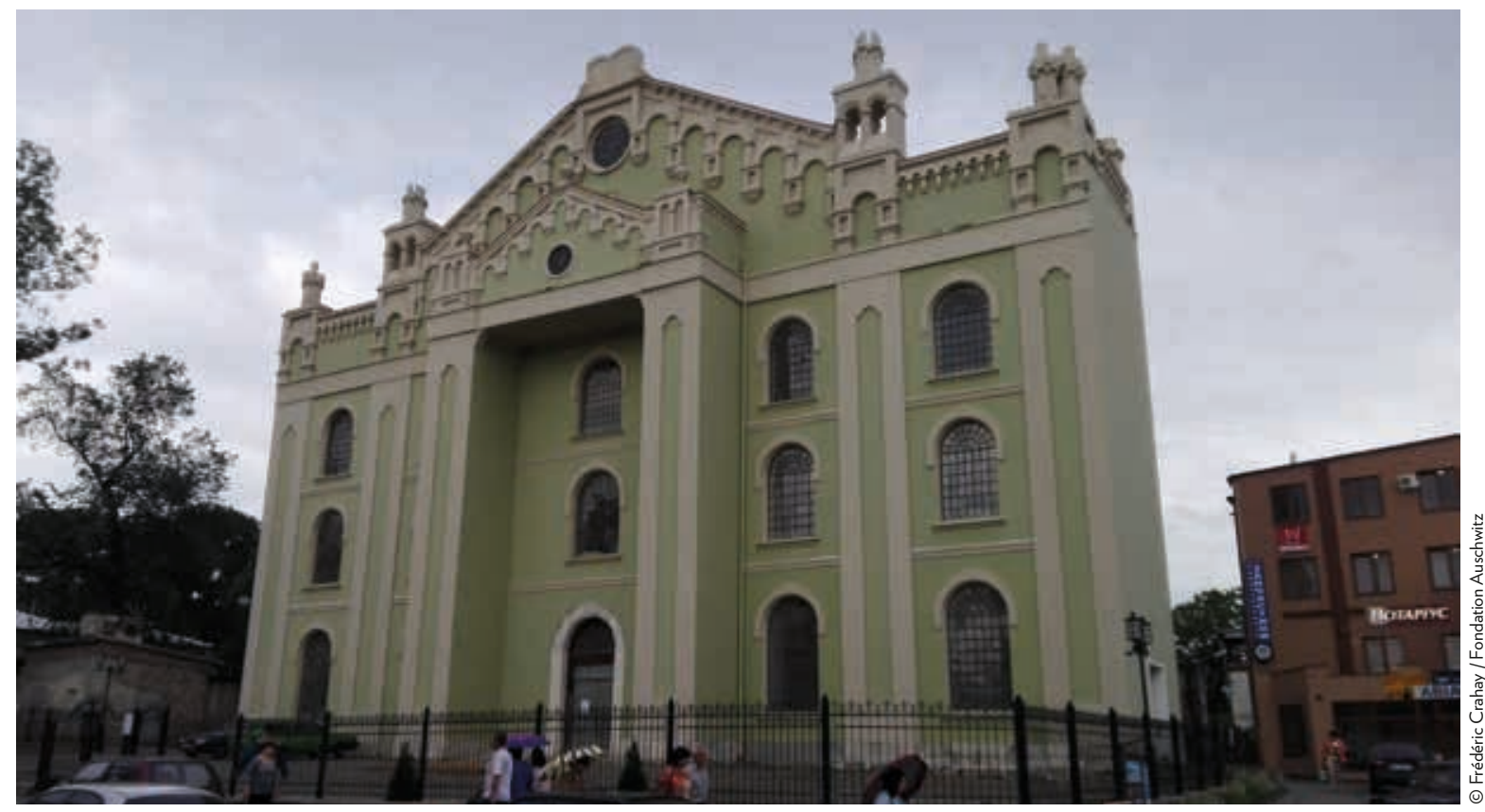

